\title{
Metastatik Meme Kanseri Tedavisinde Lapatinib Kapesitabin Kombinasyonun Etkinliğinin Retrospektif Değerlendirilmesi
}

\author{
Erdem ÇUBUKÇU ${ }^{1}$, Birol OCAK ${ }^{1}$, Ömer Fatih ÖLMEZ ${ }^{2}$, Adem DELİGÖNÜL $^{3}$, \\ Turgut KAÇAN ${ }^{4}$
}

1 Uludağ Üniversitesi Tıp Fakültesi, Tıbbi Onkoloji Bilim Dalı, Bursa.

2 Medipol Üniversitesi Tıp Fakültesi, Tıbbi Onkoloji Bilim Dalı, İstanbul.

3 İnegöl Devlet Hastanesi, Tıbbi Onkoloji Kliniği, İnegöl, Bursa.

4 S.B.Ü. Bursa Yüksek İhtisas Eğitim ve Araştırma Hastanesi, Tıbbi Onkoloji Kliniği, Bursa.

\begin{abstract}
ÖZET
Tüm dünyada meme kanseri kadınlarda kanserin ve kanser ilişkili ölümlerin en sık nedenidir. Meme kanserli hastaların \%17-30 HER2 overekspresyonu olup hastalık, kötü prognoz, hastalık progresyon riskinde artış, genel sağkalım ve progresyona kadar geçen sürenin her ikisinde azalma ile birliktedir. Lapatinib, HER2 ve epidermal büyüme faktör reseptör(EGFR) ün ilk dual tirozin kinaz inhibitörüdür. Bu çalışma da antrasiklin, taksan ve trastuzumab tedavisi sonrasında progrese olan metastatik meme kanserli hastalarda kapesitabin ve lapatinib kombinasyonunun etkisini ve tolerabilitesini inceledik. Medyan yaş 56 (34-76) olan toplam 24 hasta dosyası Eylül 2010-Mayıs 2018 arasında 3 merkezde retrospektif olarak incelendi. Tüm hastalar taksan ve antrasiklin içeren kemoterapi ve trastuzumab sonrası progrese olan HER2 pozitif metastatik meme kanseri hastalardı. Genel cevap oranı \%29.1, 2 komplet yanıt (CR, 8.3\%), 5 parsiyel yanıt (PR, 20.8\%) ve 7 stabil hastalık (SD, 29.1\%) olmak üzere sağlandı. Kapesitabin ve lapatinib kombinasyon tedavisi antrasiklin, taksan ve trastuzumab tedavisi sonrasında progrese olan metastatik meme kanserli hastalarda etkili ve iyi tolere edilmiştir.
\end{abstract}

Anahtar Kelimeler:

Retrospective Evaluation of the Efficacy of Lapatinib Capecitabine in the Treatment of Metastatic Breast Cancer

\begin{abstract}
Worldwide, breast cancer is the most common malignancy and cause of cancer-related death in women. In the $17 \%-30 \%$ of breast cancer patients who overexpress ErbB2 (HER2), the disease is associated with poorer prognosis, greater risk for disease progression and reductions in both progression free survival (PFS) and overall survival (OS). Lapatinib is the first dual tyrosine kinase inhibitor of human epidermal growth factor receptor type 2 (HER2/neu) and epidermal growth factor receptor (EGFR). The present study evaluated the efficacy and tolerability of the combination of lapatinib and capecitabine in patients with metastatic breast cancer (MBC) who progressed after therapy with trastuzumab, a taxane and/or anthracycline. A total of 24 patients with a median age of 56 (34-76) were evaluated retrospectively in 3 centers between September 2010 and May 2018. All the patients had HER2 positive MBC progressing after trastuzumab and chemotherapy including an anthracycline and/or taxane. An overall response rate (ORR) of 29.1\% was achieved including 2 complete responses (CR, 8.3\%), 5 partial responses (PR, 20.8\%), and 7 stable disease (SD, 29.1\%). Lapatinib and capecitabine combination therapy is effective and well tolerated in patients with MBC who had progressive disease after trastuzumab, taxane, and/or anthracycline therapy.
\end{abstract}

Key Words:

Geliş Tarihi: 20 Kasım 2018

Kabul Tarihi: 20 Aralık 2018

Dr. Erdem ÇUBUKÇU

Uludağ Üniversitesi Tıp Fakültesi,

Tıbbı Onkoloji Bilim Dalı,

Bursa.

Tel.: 05325245531

E-posta: erdemcubukculudag.edu.tr
Meme kanseri kadınlarda en sık görülen kanser olup tüm dünyada kanser ilişkili ölümlerde ikinci sırada yer almaktadır ${ }^{1}$. Metastatik meme kanseri kadınlarda en sık kanser ilişkili ölüm nedenidir. Tüm dünyada her yıl yaklaşık 400.000 kadın metastatik meme kanseri nedenli hayatını kaybetmektedir. Günümüzde tedavilerdeki yeni gelişmelere rağmen metastatik meme kanseri mevcut tedavi modaliteleri ile kür sağlanabilen 
bir hastalık değildir. Bu evredeki hastalarda tedavideki amaç progresyona kadar geçen süre ile genel yaşam süresini uzatmak, tümör büyümesini önlemek, semptom ve palyayonu sağlamaktır.

Meme kanserleri; klinik, morfolojik, imunohistokimyasal özelliklerine göre farklı gruplara ayrılır. Son yıllarda meme kanserlerinin tanı ve tedavisinde östrojen/progesteron reseptör varlığı ve Cerb B2 boyanma düzeyi önem kazanmıştır. Tüm meme kanserlerine baktığımızda insan büyüme faktör reseptörü 2 (HER2) yaklaşık \%15-20 lik kısmını oluşturmaktadır ${ }^{2,3}$. HER2 pozitifliği olan hastalarda prognoz kötü olup daha kötü genel yaşam süreleri daha kısa olmaktadır ${ }^{4,5}$. HER2 temelli tedavilerin metastatik meme kanserinde kullanılmaya başlanması ile beraber progresyona kadar sürelerde ve hastaların genel yaşam sürelerinde belirgin iyileşmeler sağlanmıștır. Metastatik meme kanserinde 1. basamak tedavide yaygın olarak kullanılan trastuzumab ve pertuzumab bu hastalarda yaşam sürelerine önemli derecede katkı sağlamış olup bu tedaviler altında progresyon gelişen hastalarda 2 . basamak tedavide yine HER2 temelli ilaçların kullanılması ile beklenen yaşam sürelerinde belirgin faydalar sağlanmıştır ${ }^{6,7}$.

Lapatınıb, HER2 ve epidermal büyüme faktör reseptör 1 in her ikisini de inhibe eden tirozin kinaz inhibitörüdür ${ }^{8}$. Bir çok çalışma göstermiştir ki metastatik meme kanserinde hem kemoterapi hemde hormonoterapi ile kombine olarak ya da monoterapi kullanıldığında etkinliği gösterilmiş bir ajandır ${ }^{9,10}$. Genellikle iyi tolere edilen bir ajan olup yan etkileri kolay yönetilebilmektedir. Trastuzumab tedavisi altında progrese olan metastatik meme kanserlerinde yeni ajanlar daha s1klıkla tedavi de kullanılmaya başlanılmış olsa da lapatinib ikinci basamak ve sonrasında gerek monoterapide gerekse kapesitabin ile kombinasyon tedavisinde kullanılmaktadır ${ }^{11,12}$.

Biz bu çalışmada merkezimizde lapatınıb tedavisinin yaştan bağımsız olarak trastuzumab altında progresyon gelişen hastalarda 2 . basamak ve sonrasında tek ajan yada kombinasyon tedavisinde kullanımı ile ilgili deneyimlerimizi retrospektif olarak paylaşmayı amaçladi.

\section{Gereç ve Yöntem}

Ocak 2014 ve Eylül 2018 tarihleri arasında Uludağ Üniversitesi Tıp Fakültesi, başvurmuş trastuzumab, taxan, antrasiklin kemoterapileri sonrasında progresyon gelişen ve tedavide lapatınıb kapesitabinile tedavi edilen HER2 pozitif metastatik meme kanserli hastaların dosyaları retrospektif olarak incelendi. Çalışmaya sadece metastatik olup daha öncesinde trastuzumab tedavisi altında progresyon gelişen hastalar dahil edildi.
HER2 pozitifliği immunohistokimyasal boyanma olarak 3 pozitif ya da 2 pozitif olup Fluorescence In Situ Hybridisation (FISH) ile saptanmıştır. Hastalarda cevap değerlendirmeleri Response Evaluation Criteria in Solid Tumors (RECIST) kriterlerine göre yapılmıştir.

Tedavide lapatinib dozu 1250 mg/gün sabit doz devamlı ve kapesitabin dozu $2000 \mathrm{mg} / \mathrm{m} 2$ gün 14 gün verilip 1hafta boş geçilmiş siklus 21 günde bir tekrarlanmıştır. Yan etki durumuna göre doz modifikasyonları yapılmıştır.

Yan etki ölçümleri National Cancer Institute Common Toxicity Criteria (NCI-CTC) skorlama ile yapılmıştır. Hastalarda kardiyak değerlendirme tedavi önce yapılmış ve hastaların kardiyak fraksiyonları ekokardiyografi ile ölçülmüştür.

\section{Bulgular}

Ocak 2010 ve Eylül 2018 meme kanseri tanısı almış ve HER2 pozitif metastatik meme kanserli tüm hastalar tarandı ve 24 hasta değerlendirildi. Hastaların ortalama yaşı 56 (34-76) idi. Hastalardan 12 tanesi (\%50) 2. basamak tedavide, 6 tanesi (\%25) 3. basamak tedavide ve diğer hastalar 4 . basamak ve sonrasında lapatinib + kapesitabin almışlardır. (Tablo I) Hastalardan 4 tanesi (\%16.6) tedaviye devam ediyor olup 2 hastada (\%8.3) tedavi süresi 2 yılın üzerindedir. 2 hastada (\%8.3) komplet yanıt, 5 hasta (\%20.8) parsiyel yanıt, 7 hastada (\%29.1) stabil hastalık elde edilirken, 10 hastada (\%41.6) progresif hastalık saptanmıştır. Tedavinin genel cevap oranlar1 \%29.1 iken, klinik fayda oran1 \%58.4 olarak bulunmuştur. Medyan progresyona kadar geçen süre 8 ay iken medyan genel yaşam süresi 13 ay bulunmuştur. (Tablo II) Hastalardan 6 tanesi (\%25) tedaviye başlamadan önce kranial metastazı mevcut iken, 4 tanesinde (\%16.6) takiplerinde kranial metastataz gelişmiştir.

Tablo I. Hasta genel özellikleri

\begin{tabular}{|lc|}
\hline Hasta sayısı & 24 \\
Medyan yaş & $56(34-76)$ \\
Tedavi basamağı & \\
2.basamak & 12 tanesi (\%50) \\
3.basamak & 6 tanesi (\%25) \\
4. basamak ve ötesi & 6 tanesi (\%25) \\
\hline
\end{tabular}

Tablo II. Tedavi cevap oranları

\begin{tabular}{|ll|}
\hline Yanıt oranları & \\
Komplet yanıt & $2(\% 8.3)$ \\
Parsiyel yanıt & $5(\% 20.8)$ \\
Stabil hastalık & $7(\% 29.1)$ \\
Progresif hastalık & $10(\% 41.6)$ \\
\hline
\end{tabular}




\section{Metastatik Meme Kanseri Tedavisinde Lapatinib Kapesitabin}

Kombinasyon tedavisi genellikle iyi tolere edildi. En sık gözlenen yan etkiler yorgunluk diyare el ayak sendromu ve kusma olarak saptandi. 3 hasta grade 3 ve üstü diyare nedeniyle tedaviye devam edemedi. 2 hastada total $1000 \mathrm{mg}$ lapatinib dozu ile tedaviye devam edildi. Kapesitabine bağlı bir hastada grade 4, 3 hastada grade 3 el ayak sendromu gelişti. Toplam 6 hastada el ayak ve mukozit nedeniyle kapesitabin dozu 1500 mg/m2 günlük doza inildi. Hastalarda yönetilebilir nötropeni görülmekle beraber febril nötropeni gözlenmedi. (Şekil I)

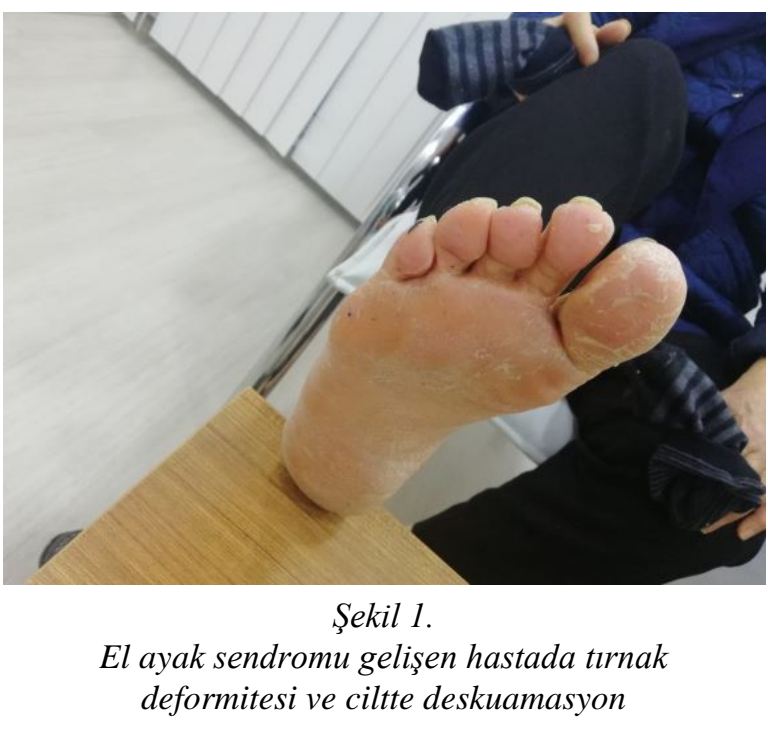

\section{Tartışma}

Metastatik meme kanserinde 1 . basamak tedavide son y1llarda standart tedavi haline gelen trastuzumab ve pertuzumab yaşam sürelerine önemli derecede katk1 sağlamış olsada tam kür edilen hasta sayısı çok az$\mathrm{d}_{1} \mathrm{r}^{13-15}$. Bu tedaviler altında progresyon gelişen hastalarda 2. basamak tedavide yine HER2 temelli ilaçların kullanılması ile beklenen yaşam sürelerinde belirgin faydalar sağlanmıştır ${ }^{16,17}$. Laptinib ve kapesitabin kombinasyon tedavisi 2. basamakta yaklaşık 10 yıldır ülkemizde kullanılmakla birlikte son yıllarda yeni nesil anti HER2 tedavilerden trastuzumab emtansine (TDM-1) kullanılmaya başlanması ile beraber hastalarda kullanım daha ileri basamaklara kalmıştır.

Retrospektif olan deneyimimizde trastuzumab, taxan, antrasiklin kemoterapileri sonrasında progresyon gelişen metastatik HER2 pozitif meme kanseri hastalarında lapatinib ve kapesitabin kombinasyonunun iyi tolere edildiği ve cevap oranlarını \%29.1 olarak saptadık. Yapılan iki büyük çalışma olan Lapatinib Expanded Access Program ${ }^{18}$ ve EGF100151 ${ }^{19}$ çalışmaları ile kıyaslandığında yan etki oranlarımızın ve genel cevap oranlarımızın daha az olduğu görülmektedir. Bu durum çalışmamızın tek merkezli yapılan az hasta sayılı ve retrospektif küçük bir çalışma özelliğinden kaynaklanmakta olduğunu düşündürmektedir.
Metastatik meme kanserinde beyin metastazı sıklıkla karşılaşılan bir klinik durumdur. Genel olarak neredeyse tüm metastatik meme kanserli hastaların yaklaş1k \%10 oranında saptanabilirken triple negatif meme kanserinde otopsi serilerinde bu oran \%30-40 oranlarına kadar çıkmaktadır. Trastuzumab tedavisi alan hastalarda nerdeyse üçte bir oranında kranial metastaz gelişebilmektedir. Bazen klinik olarak tüm metastazlar tedavi altında cevaplı hatta tam yanıtlı iken hastalarda yaygın kranial metastaz gelişebilmektedir ${ }^{20-22}$. Geyer ve arkadaşlarının 2006 yılında New England Journal of Medicine de yayınladıkları faz 3 çalışmada ${ }^{23}$ tek ajan kapesitabin tedavisine lapatinib eklendiğinde kranial metastazlı hastalar da daha etkin yanıt aldıklarını göstermişlerdir. Çalışmamızda 6 hastada tedaviye başlarken beyin metastazı saptanmış olup tedavi altında 2 hastada yeni beyin metastazı gelişmiştir.

Retrospektif olan çalışmamızda en sık gözlenen yan etkiler literatüre benzer şekilde yorgunluk, diyare, el ayak sendromu ve kusma olarak saptand1. 3 hasta da grade 3 ve üstü diyare nedeniyle tedaviye devam edemedi. Kapesitabine bağlı 1 hastada grade 4, 3 hastada grade 3 el ayak sendromu gelişti. Toplam 6 hastada el ayak ve mukozit nedeniyle kapesitabin dozu düşürülmüş ya da doz atlanılması yapılmış olduğu saptandı. Hastalarda yönetilebilir nötropeni görülmekle beraber febril nötropeni gözlenmedi. Kardiyak problem nedeniyle tedaviye devam edememe durumu saptanmadi. Çalışmamızda yan etkiler incelendiğinde literatürle kıyaslandığında daha düşük bulunmuştur. Bu durum retrospektif bu çalışmada yan etkilerin düzenli not edilmemesine bağlı olabilir. Çalışmamızda altmış beş yaş üstü 4 hastada da benzer sonuçlar elde edilmiş olup 1 hasta ishale bağlı lapatinib dozunu $750 \mathrm{mg}$ olarak devam etmiştir.

Sonuç olarak, metastatik meme kanserinde yeni tedavilerin kullanılmaya başlanması ile beraber genel yaşam sürelerinde belli oranda düzelmeler sağlanmıştır. Özellikle HER2 pozitif metastatik meme kanserli hastalarda bu fayda kayda değer derecede yüksektir. $\mathrm{Bu}$ hastalarda tedavinin tüm aşamalarında HER yolağının inhibe edilmesi önemidir. Günümüzde 2 basamak tedavide her ne kadar yeni ajan bir olan TDM-1 tercih edilse de, uygun hastalarda 2 . basamakta ya da sıralı tedavide sonraki basamaklarda HER2 inhibisyonu için kolay yönetilebilir yan etki ve kullanım kolaylığ1 ile lapatinib kapesitabin kombinasyonu seçenek olarak yerini korumaktadır.

\section{Kaynaklar}

1. Siegel RL, Miller KD, Jemal A. Cancer statistics,2016. CA Cancer J Clin2016;66:7-30.

2. Zahnow CA. ErbB receptors and their ligands in the breast. Expert Rev Mol Med 2006; 8: 1-21. 


\section{E. Çubukçu, ark.}

3. Zhang H, Berezov A, Wang Q et al. ErbB receptors: from oncogenes to targeted cancer therapies. J Clin Invest 2007; 117 2051-58

4. Badache A, Goncalves A. The ErbB2 signaling network as a target for breast cancer therapy. J Mammary Gland Biol Neoplasia 2006; 11: 13-25.

5. Slamon DJ, Godolphin W, Jones LA et al. Studies of the HER2/neu proto-oncogene in human breast and ovarian cancer. Science 1989; 244: 707-12.

6. Swain SM, Baselga J, Kim SB, et al. CLEOPATRA Study Group. Pertuzumab, trastuzumab, and docetaxel in HER2 positive metastatic breast cancer. N Engl J Med. 2015; 19;372(8):724-34.

7. Gamucci T, Pizzuti L, Natoli C, Mentuccia L, Sperduti I, Barba M, A multicenter REtrospective observational study of firstline treatment with PERtuzumab, trastuzumab and taxanes for advanced HER2 positive breast cancer patients. RePer Study. Cancer Biol Ther. 2018; 7:1-9.

8. Medina PJ, Goodin S. Lapatinib: a dual inhibitor of human epidermal growth factor receptor tyrosine kinases. Clin Ther. 2008;30(8):1426-47.

9. Johnston S, Pegram M, Press M et al. Lapatinib combined with letrozole vs. letrozole alone for front line postmenopausal hormone receptor positive (HR+) metastatic breast cancer (MBC): first results from the EGF30008 Trial. Abstract presented at 31st Annual San Antonio Breast Cancer Symposium; December 10-14, 2008;

10. Ro J, Park S, Kim S, et al. Clinical outcomes of HER2-positive metastatic breast cancer patients with brain metastasis treated with lapatinib and capecitabine: an open-label expanded Access study in Korea. BMC Cancer. 2012;28;12:322-3.

11. Di Leo A, Gomez HL, Aziz Z,et al. Phase III, double-blind, randomized study comparing lapatinib plus paclitaxel with placebo plus paclitaxel as firstline treatment for metastatic breast cancer. J Clin Oncol. 2008;26:5544-52.

12. Gomez HL, Doval DC, Chavez MA, et al. Efficacy and safety of lapatinib as firstline therapy for HER2-amplified locally advanced or metastatic breast cancer. J Clin Oncol 2008;26:29993005

13. Giordano SH, Temin S, Kirshner JJ, et al. Systemic therapy for patients with advanced human epidermal growth factor receptor 2-positive breast cancer: American Society of Clinical Onco- logy Clinical Practice Guideline. J Clin Oncol 2014;32:207899.

14. Leung HWC, Leung JH, Chan ALF. Efficacy and safety of a combination of HER2-targeted agents as first-line treatment for metastatic HER2-positive breast cancer: a network metaanalysis. Expert Opin Drug Saf. 2018;17(1):1-7.

15. Tian T, Ye J, Zhou S. Effect of pertuzumab, trastuzumab, and docetaxel inHER2-positive metastatic breast cancer: A metaanalysis . Int J Clin Pharmacol Ther. 2017;55(9):720-727.

16. Perez EA, Barrios C, Eiermann Wet al. Trastuzumab Emtansine With or Without Pertuzumab Versus Trastuzumab Plus Taxane for Human Epidermal Growth Factor Receptor 2-Positive, Advanced Breast Cancer: Primary Results From the Phase III MARIANNE Study. J Clin Oncol. 2017 Jan 10;35(2):141-48.

17. Fabi A, De Laurentiis M, Caruso M, et al.. Efficacy and safety of T-DM1 in the 'common-practice' of HER2+ advanced breast cancer setting: a multicenter study. Oncotarget 2017 18;8(38):64481-89.

18. Capri G, Chang J, Chen SC, et al. An open-label expanded access study of lapatinib and capecitabine in patients with HER2-overexpressing locally advanced or metastatic breast cancer. Ann Oncol 2010;21(3):474-80.

19. Cameron D, Casey M, Press M, et al. A phase III randomized comparison of lapatinib plus capecitabine versus capecitabine alone in women with advanced breast cancer that has progressed on trastuzumab: updated efficacy and biomarker analyses. Breast Cancer Res Treat 2008;112:533-43.

20. Clayton AJ, Danson S, Jolly S, et al. Incidence of cerebral metastases in patients treated with trastuzumab for metastatic breast cancer. Br J Cancer 2004;91:639-43.

21. Lin NU, Bellon JR, Winer EP. CNS metastases in breast cancer. J Clin Oncol 2004;22:608-17.

22. Cetin B, Benekli M, Oksuzoglu B, et al. Lapatinib plus capecitabine for brain metastases in patients with human epidermal growth factor receptor 2-positive advanced breast cancer. Onkologie 2012;35:740-45.

23. Geyer CE, Orster J, Lindquist D, et al. Lapatinib plus capecitabine for HER2- positive advanced breast cancer N Engl J Med. 2006;355:2733-43. 